daily given in liquid form before meals and at bedtime was started. After three months' treatment, biopsy specimens obtained from the gastric body and antrum showed the disappearance of the chronic inflammatory infiltrate (Fig. 3). There was concomitant clinical improvement with improvement in appetite and weight gain. Serum eosinophil concentrations returned to normal values.

\section{Discussion}

Diffuse varioliform gastritis, although occurring uncommonly in adults $(0.5 \%$ of gastroscopic findings), has never been reported in children. The studies of André et al in adults contribute to the understanding of this lesion. ${ }^{3}$ These authors found large numbers of plasma cells containing $\operatorname{IgE}$ in the gastric mucosa of the affected subjects and an increased incidence of asthma, eczema, urticaria, eosinophilia, and raised serum IgE concentrations. They suggested that excessive histamine release, which gives rise to the gastric gland hyperplasia, has a central role in the pathogenesis of the disease.

The data emerging from examination of this patient excluded the more common forms of chronic gastritis, whereas the increase in total serum $\operatorname{IgE}$ and eosinophil concentrations, the low concentrations of IgA in the saliva, and the positive radioallergosorbent and skin prick tests to inhalant allergens suggested a type I allergic pathogenesis. In affected adults, Rosen et al observed an increased rate not only of positive food radioallergosorbent tests but also of positive inhalant radioallergosorbent tests. ${ }^{2}$

There is, therefore, the possibility that in our patient, for reasons unknown, there is an $\operatorname{IgE}$ response in the gastric mucosa. In our patient, as in 10 adults studied by André, ${ }^{4}$ we found a normal stomach acid output.

In a randomised placebo controlled, double blind trial with sodium cromoglycate carried out in affected adults, André et al have stated that oral treatment with sodium cromoglycate showed clinical and endoscopic improvement with reduction of $\mathrm{IgE}$ containing cells in the gastric mucosa. Treatment with cimetidine, on the contrary, showed no appreciable improvement. ${ }^{4}$

The efficacy of sodium cromoglycate might therefore reside in its ability to interrupt the vicious circle of macromolecule (allergen) absorption, mediator release, and increased mucosal permeability. Our report shows that a similar treatment may also be beneficial in children.

\footnotetext{
References

${ }^{1}$ Lambert R, André C, Moulinier B, Bugnon B. Diffuse varioliform gastritis. Digestion 1978;;17:159-67.

2 Rosen SN, Bennett MK, Faux J, Jewell DP. Chronic gastritisan allergic disorder? Proceedings of the second Fisons food allergy workshop. Oxford: Medicine Publishing Foundation, 1983:73-6.

3 André C, Moulinier B, André F, Daniere S. Evidence for anaphylactic reactions in peptic ulcer and varioliform gastritis. Ann Allergy 1983;51:325-8.

${ }^{4}$ André C, Gillon J, Moulinier B, Martin A, Fargier MC. Randomised placebo-controlled double-blind trial of two dosages of sodium cromoglycate in treatment of varioliform gastritis: comparison with cimetidine. Gut 1982;23:348-52.
}

Correspondence to Dr R Caporali, Divisione di Pediatria, Via Turati, Bibbiena, Arezzo, Italy.

Received 2 January 1986

\title{
Twenty year review of duodenal ulcer
}

\author{
J S A COLLINS, J F T GLASGOW, T G TROUTON, AND R J McFARLAND
}

Departments of Medicine and Child Health, The Queen's University of Belfast and The Ulster Hospital, Belfast

SUMMARY Of 31 patients ( 18 male and 13 female) followed up 13-29 years after diagnosis, recurrent or persistent duodenal ulcer had occurred in four. In 22 (71\%) gastrointestinal symptoms persisted into adult life, although only abdominal pain was significantly more frequent than in 126 controls.

Few long term studies of childhood duodenal ulcer have been published, although it has been suggested that there is a high rate of recurrence and that gastrointestinal symptoms often persist into adult life. ${ }^{1}$ This study reviewed patients from a group reported by Robb et $a l^{2}$ who had an ulcer diagnosed on barium meal examination between 1961 and 1970 and compared their gastrointestinal symptoms with those of apparently healthy adult controls.

\section{Methods}

A detailed questionnaire was administered that embraced various aspects of the patient's life, including social habits, gastrointestinal symptoms 
since 16 years of age, visits to the family doctor, outpatient clinics, and hospital admissions or treatments. Proof of ulcer recurrence was obtained by consulting hospital records. Patients currently symptomatic were offered upper gastrointestinal endoscopy.

A similar questionnaire was completed in 126 controls who had been admitted for extraction of wisdom teeth. Frequency of symptoms between the study group and controls were compared using the Mantel Haenszel method for pooling.

\section{Results}

Of 49 patients, 31 ( 18 men, 13 women) were traced 13-29 (median 21.0) years after initial diagnosis, which had been at a median age of 8.7 years. At interview, the study group were aged between 19 and 42 (median 30.5 ) years, and the 126 subjects in the control group ( 43 men, 83 women) between 14 and 42 (median 28.0 ) years.

After the age of $16,22(71 \%)$ of the study group had had intermittent symptoms, but only abdominal pain was significantly more frequent than in controls (Table ) and tended to be localised more often in the epigastrium. Abdominal pain had occurred at least one or two times weekly in five study patients and at least one or two times monthly in a further 12 . As there were more women among the controls (the male:female ratio being roughly $1: 2$ ) this sex difference was allowed for using the Mantel Haenszel method with $2 \times 2$ contingency tables.

Four men in the study group had had a proven ulcer recurrence after 16 years of age, of whom two had developed bleeding and one a perforation. Two of the men with ulcer recurrence had subsequently undergone truncal vagotomy and pyloroplasty.

Of 11 patients symptomatic at review, endoscopy was carried out in five. Of these, three were normal, one had a duodenal ulcer, and one had a scarred duodenal cap with erosive duodenitis. Comparison within the study group of the 22 symptomatic with the nine asymptomatic patients showed no differences in social habits, family history, or age at initial diagnosis.

Table Comparison of symptom frequency between study and control groups. Values are No (\%)

\begin{tabular}{lll}
\hline Symptom & $\begin{array}{l}\text { Study group } \\
(n=31)\end{array}$ & $\begin{array}{l}\text { Control group } \\
(n=126)\end{array}$ \\
\hline Abdominal pain & $17(55)$ & $18(14)^{*}$ \\
Gastro-oesophageal reflux & $10(32)$ & $23(18)$ \\
Vomiting & $5(16)$ & $11(9)$ \\
Diarrhoea & $3(10)$ & $7(5)$ \\
Constipation & $3(10)$ & $5 \quad(4)$ \\
\hline${ }^{*} \mathrm{p}<0 \cdot(001$. & &
\end{tabular}

\section{Discussion}

This review study of 31 children with duodenal ulcer found that the proven recurrence rate is low, although a higher frequency $(71 \%)$ of recurrent gastrointestinal symptoms continued into adult life. In only four males $(13 \%)$, who complained of having epigastric pain at least one or two times weekly, has an endoscopic diagnosis been made of persistent or recurrent ulcer. There are few studies that can be directly compared with our findings. The Dublin workers noted persistent symptoms in 22 of 28 patients managed medically, of whom only two had radiological evidence of an ulcer crater, although in 11 the duodenal cap was deformed. ${ }^{2}$ At long term follow up White and colleagues found recurrent ulceration in $49 \%$ of 41 children. ${ }^{3}$ The recurrence rate in our study might conceivably have been higher if all 11 patients who were symptomatic at review had had endoscopy.

Several authors have noted a high recurrence rate in childhood duodenal ulcer after medical treatment, but most have favoured surgery only for complications. ${ }^{4}$ In our study only two out of 49 required surgery in childhood, the remainder being treated with a combination of diet and antacids. No studies on the effect of long term $\mathrm{H} 2$ antagonist maintenance therapy in children have been published. In our patients four $(13 \%)$ had taken these drugs at some time between 1977 and 1984, and of these two had proven ulcer recurrence.

Diagnosis in the original group of 49 children was based on barium screening and most review studies of childhood duodenal ulcer have been based on radiological diagnosis. ${ }^{1-3} \mathrm{~A}$ recent study compared the results of barium examination with endoscopy in 89 children with dyspeptic symptoms and in only 10 $(11 \%)$ was duodenal ulcer confirmed endoscopically after abnormal radiology. ${ }^{5}$ This small proportion must be noted in any review of cases diagnosed in the pre-endoscopic era.

\footnotetext{
References

${ }^{1}$ Puri P, Boyd E, Blake N, Guiney EJ. Duodenal ulcer in childhood: a continuing disease in adult life. $J$ Paediatr Surg 1978;13:525-7.

2 Robb JDA, Thomas PS, Orszulock P, Odling-Smee GW Duodenal ulcer in children. Arch Dis Child 1972;47:688-96.

${ }^{3}$ White A, Carachi R, Young DG. Duodenal ulceration presenting in childhood. Longterm follow-up. $J$ Paediatr Surg 1984;19:6-8.

${ }^{4}$ Baida M, McIntyre JA, Deitel M. Peptic ulcer in children and adolescents. Arch Surg 1969;99:15-8.

5 Miller V, Doig CM. Upper gastrointestinal endoscopy. Arch Dis Child 1984;59:1100-2.
}

Correspondence to Dr J S A Collins, Department of Medicine, Institute of Clinical Science, Grosvenor Road, Belfast BT12 6BJ, Northern Ireland.

Received 8 January 1986 